\title{
EWSR1 Gene
}

National Cancer Institute

\section{Source}

National Cancer Institute. EWSR1 Gene. NCI Thesaurus. Code C18322.

This gene may play a role in post-transcriptional regulation; however the function remains to be elucidated. Mutations in the gene result in Ewing sarcoma and other tumors. 